\title{
Measurement of bronchial responsiveness by forced oscillation technique in occupational epidemiology
}

\author{
J.C. Pairon*t, Y. Iwatsubo*, C. Hubert*, H. Lorino**, \\ H. Nouaigui++, R. Gharbi++, P. Brochard*+
}

Measurement of bronchial responsiveness by forced oscillation technique in occupational epidemiology. J.C. Pairon, Y. Iwatsubo, C. Hubert, H. Lorino, H. Nouaigui, R. Gharbi, P. Brochard. CERS Journals Ltd 1994.

ABSTRACT: The performance of the forced oscillation technique (FOT) in the assessment of bronchial responsiveness on the methacholine challenge test was compared with that of forced expiratory volume in one second $\left(\mathrm{FEV}_{1}\right)$ in 119 active workers with normal baseline pulmonary function.

Changes in resistance $\left(\Delta \mathbf{R}_{0} \%\right)$, frequency dependence of resistance $(\Delta P)$ and resonant frequency $(\triangle \mathrm{F} \%)$ determined by the FOT were compared to the $\Delta \mathrm{FEV}_{1} \%$. Receiver operating characteristic (ROC) curves were established to determine values of the changes in FOT parameters which corresponded to the best sensitivity and specificity for classifying the subjects as hyperresponsive or nonresponsive on the methacholine challenge test.

Significant correlations were observed between $\Delta \mathrm{FEV}_{\mathbf{1}} \%$ and $\Delta \mathbf{R}_{\mathbf{0}} \%, \Delta \mathbf{P}$ and $\Delta \mathbf{F} \%$ respectively. The ROC curves showed the following cut-off values of FOT parameters to be the best values for classifying the subjects according to the presence or absence of $20 \%$ fall in $\mathrm{FEV}_{1}$ : a $65 \%$ increase in $\mathrm{R}_{0}$ (sensitivity $75 \%$; specificity: $76 \%$ ); a decrease of $65 \times 10^{-3} \mathrm{hPa} \cdot l^{-1} \cdot \mathrm{s}^{2}$ in $\mathrm{P}$ (sensitivity $58 \%$; specificity $83 \%$ ); a $50 \%$ increase in $\mathrm{F}$ (sensitivity $75 \%$; specificity $62 \%$ ).

Our results suggest that the FOT is a useful test for assessment of bronchial hyperresponsiveness when compared to spirometry, and can be applied to epidemiological studies of a bronchial challenge test in normal active working populations.

*INSERM Unité 139, Créteil, France. +Institut InterUniversitaire de Médecine du Travail de Paris-Ile de France, Paris, France. **INSERM Unité 296, Créteil, France. ${ }^{++}$Institute of occupational medicine and ergonomy, Faculté de Médecine, Tunis, Tunisia.

Correspondence: J.C. Pairon

INSERM Unité 139

Hôpital H. Mondor

51 avenue du Maréchal de Lattre de Tissigny F-94010 Créteil Cedex

France

Keywords: Airway reactivity, epidemiology, occupation, respiratory impedance, sensitivity, specificity

Received: June 41993

Accepted after revision October 131993

This study was supported by a grant from the Tunisian Ministère de l'Education Nationale et de l'Enseignement Supérieur, the Faculté de Médecine de Tunis (Tunisia), and the Comité Départemental de Lutte contre les Maladies Respiratoires du Val de Marne (France).
Exposure to respiratory irritants or mineral particles in the workplace has been reported as a possible risk factor of bronchial hyperresponsiveness (BHR) [1-4]. A decline in respiratory function has been observed among subjects with BHR, suggesting that the latter might be a predisposing factor of bronchopulmonary obstructive disease $[5,6]$. In a longitudinal study of iron mine workers, PHAM et al. [7] observed that the incidence of chronic bronchitis was higher and the decrease in forced expiratory volume in one second/forced vital capacity ratio $\left(\mathrm{FEV}_{1} / \mathrm{FVC}\right)$ more marked among hyperreactive subjects. These studies suggest the importance of early detection of BHR in groups exposed to respiratory pollutants.

Measurement of BHR is usually based on conventional indices of forced expiratory manoeuvres, such as the dose of methacholine inducing a $20 \%$ decline in $\mathrm{FEV}_{1}$ [8]. However, forced expiratory tests may present some disadvantages in practice. These tests are effortdependent, thus requiring the active co-operation of the subject. Moreover, forced inspiration may influence bronchial tone and, consequently, affect the bronchial response, underestimating the effect of bronchoconstrictor agents [8, 9].

An alternative method of measuring pulmonary function is the assessment of respiratory impedance by the forced oscillation technique (FOT), which is increasingly performed in pulmonary function studies. This method has the major advantage of being a simple method, requiring only the passive co-operation of the subject, who breathes quietly at tidal volume during the test [10-12].

As regards the performance of the FOT in the evaluation of BHR, most studies [13-16] have shown a fair correlation between the forced oscillation parameters and the classical forced expiratory test parameters. These validation studies were based mainly on asthmatic patients. As far as we know, no study has been conducted in working populations for which the simplicity of the FOT could constitute a substantial advantage.

The aim of the present study was to assess the performance of the FOT in comparison with spirometry during a bronchial challenge test in a Tunisian working population with normal baseline pulmonary function. 


\section{Subjects, materials and methods}

\section{Subjects}

The present study was based on a cross-sectional survey conducted in Tunisia. One hundred and nineteen male active workers of three occupational groups participated in the study; the first group consisted of 48 blue collar workers at a chemical industrial plant (production of pesticides) in the region of Gabes, who were exposed to low levels of $\mathrm{SO}_{2}$ and $\mathrm{NO}_{x}$; the second group consisted of 41 office workers at the same plant, and the third group consisted of 30 subjects working in the hotel trade in the region of Bizerte. The last two groups were free of any known present exposure to respiratory pollutants. The study was conducted over one month in April 1989, and all tests were performed within each workplace. The subjects included were those actually at work during this period who agreed to participate in the present survey. Furthermore, subjects with $\mathrm{FEV}_{1}$ less than $80 \%$ of the European Community for Coal and Steel reference values [17] were excluded from the study.

The mean age of the subjects was 34 yrs (SD 7 yrs). Fifty eight percent of the subjects were smokers, with a mean cumulative tobacco consumption of 10 packyears (SD 9 pack-years). The mean duration of employment was 11 yrs (SD 7 yrs). For the baseline FVC and $\mathrm{FEV}_{1}$, the average ratios of observed to reference values were close to unity, confirming that the subjects were reasonably healthy (percentages of predicted value were $96 \pm 10$ and $97 \pm 10$ for FVC and $\mathrm{FEV}_{1}$, respectively).

\section{Data collection}

Questionnaire. Information on demographic data and smoking habits was obtained by means of a standardized questionnaire.

Spirometry. A lung function test was carried out in each workplace using a spirometer Vicatest ${ }^{\circledR}$ No. 5. The parameters measured included FVC and $\mathrm{FEV}_{1}$. For these two parameters, the reference values of the European Community for Coal and Steel [17] were used to calculate the ratios of measured to reference values.

Three manoeuvres were executed, and the best $\mathrm{FEV}_{1}$ and FVC values were retained [17].

Forced oscillation method. Respiratory impedance was determined by means of the standard FOT, as described previously $[10,11]$. Pressure oscillations, generated by two loudspeakers, were applied to the subject's mouth, while he was comfortably seated with his elbows on the table and his cheeks firmly supported. The excitation was a band-pass filtered random noise with a frequency content ranging from $3-25 \mathrm{~Hz}$. Flow was sensed by a Lilly type pneumotachograph (Jaeger, Wurzburg; resistance $\left.0.35 \mathrm{hPa} \cdot \mathrm{s} \cdot l^{-1}\right)$ connected to a differential pressure transducer (Sensym SCX OID, $\pm 70 \mathrm{hPa}$ ), and pressure was sensed by a similar transducer. Both signals were low-pass filtered at $25 \mathrm{~Hz}$, and then sampled at 128 $\mathrm{Hz}$ for periods of $12 \mathrm{~s}$. Auto and cross-spectra of flow and pressure were estimated every $0.25 \mathrm{~Hz}$ for adjacent $4 \mathrm{~s}$ blocks and averaged over each $12 \mathrm{~s}$ period to yield an estimate of the impedance and coherence function $\left(\gamma^{2}\right)$. Spectra were then averaged again over three $12 \mathrm{~s}$ periods in which more than $80 \%$ of the coherence values were higher than 0.8 between 3 and $25 \mathrm{~Hz}$. A single estimate of the real ( $\mathrm{Zr})$, and imaginary components (Zi) of impedance and coherence function was, thus, obtained as a function of frequency $(f)$.

A simple description of impedance data corresponding to $\gamma^{2}>0.8$ was obtained as follows. Resistance was described by a linear model: $\mathrm{Zr}=\mathrm{R}_{0}+\mathrm{P} \times f$, where $\mathrm{R}_{0}$ is the extrapolated resistance at zero frequency and $\mathrm{P}$ accounts for the frequency dependence of resistance; $\mathrm{Zi}$ was characterized by the resonant frequency $(F)$, which was evaluated as the frequency at which $\operatorname{Zi}(f)=0$.

Methacholine challenge testing. Bronchial challenge testing was performed using solutions containing $1.25 \%$ of methacholine, which was delivered by a Mediprom ${ }^{\circledR}$ dosimeter. Each inhalation delivered $50 \mu \mathrm{g}$ of methacholine. Pulmonary function tests were performed at cumulative doses of $100,300,600$ and $1000 \mu \mathrm{g}$. The forced expiratory manoeuvres were systematically executed before and at the end of the methacholine challenge test, but not at the intermediate doses. By contrast, the forced oscillation manoeuvres were performed 1 min after the end of each aerosol breathing period. The challenge test was continued until $\mathrm{R}_{0}$ exhibited a twofold increase. In this case, the $\mathrm{FEV}_{1}$ was measured. If the subject exhibited a $20 \%$ decline in $\mathrm{FEV}_{1}$ from the baseline value, the challenge test was stopped. Otherwise, the test was continued until the highest concentration of methacholine was reached. The test was also stopped when the subject complained of respiratory symptoms.

Data analysis. The results from the methacholine challenge test for spirometric data were examined using two types of index:

1) Percentage decline in $\mathrm{FEV}_{1}$ as a qualitative measure of BHR, which is usually defined by a $20 \%$ decline in $\mathrm{FEV}_{1}$ [18]; nevertheless, some authors have suggested that a lower level of change could indicate the presence of BHR [7, 19, 20]; in the present study, three threshold values were considered: 20,15 and $10 \%$ fall in $\mathrm{FEV}_{1}$ where $\triangle \mathrm{FEV}_{1} \%$ was defined by the following relation:

$$
\Delta \mathrm{FEV}_{1} \%=\frac{\text { baseline } \mathrm{FEV}_{1}-\mathrm{FEV}_{1} \text { at the final dose }}{\text { baseline } \mathrm{FEV}_{1}}
$$

2) A dose-response slope as a quantitative measure of BHR calculated for each subject as:

$$
\frac{\Delta \mathrm{FEV}_{1} \%}{\text { cumulative dose of methacholine inhaled }}
$$

according to O'CONNOR et al. [21]. 
Similar indices were examined for the forced oscillation parameters:

$$
\Delta \mathrm{R}_{0} \%=\frac{\mathrm{R}_{0} \text { at final dose }- \text { baseline } \mathrm{R}_{0}}{\text { baseline } \mathrm{R}_{0}}
$$

$\Delta \mathrm{P}=\mathrm{P}$ at final dose - baseline $\mathrm{P}$

Where $\mathrm{P}=$ frequency dependence of resistance. ( $\Delta \mathrm{P}$ was chosen instead of $\Delta \mathrm{P} \%$ because the baseline values of $\mathrm{P}$ are distributed around zero in healthy subjects);

$$
\Delta \mathrm{F} \%=\frac{\mathrm{F} \text { at final dose-baseline } \mathrm{F}}{\text { baseline } \mathrm{F}}
$$

where $\mathrm{F}=$ resonant frequency.

2) Dose-response slopes were established for each parameter by dividing the previous forced oscillation indices by the cumulative dose of methacholine.

The relationships between FOT and spirometry were examined considering the latter as the reference. Firstly, forced oscillation parameters were compared at each cumulative dose of methacholine between responsive $\left(\Delta \mathrm{FEV}_{1} \%\right.$ greater than $\left.20 \%\right)$ and normal subjects $\left(\Delta \mathrm{FEV}_{1} \%\right.$ less than $\left.20 \%\right)$ using the Wilcoxon nonparametric test. Secondly, Pearson correlation coefficients between spirometric and forced oscillation indices were calculated. Finally, sensitivity and specificity of the variations in forced oscillation parameters during bronchial challenge test were examined by receiver operating characteristic (ROC) curves [22] according to the presence of BHR, defined by 10,15 and $20 \% \triangle \mathrm{FEV}_{1}$. ROC curves made it possible to show the true positive rate (sensitivity) versus the false positive rate (1 - specificity) at various levels of change in FOT parameters, and to determine the cut-off value corresponding to the greatest number of well-classified subjects.

All statistical analyses were performed using the SAS software package.

\section{Results}

The baseline forced oscillation parameters were not normally distributed (fig 1). Table 1 shows the baseline value and the variation of these parameters at each cumulative dose.

Table 1. - Changes in forced oscillation parameters during bronchial challenge test

\begin{tabular}{lccccc}
\hline Treatment & $\begin{array}{c}\text { Subjects } \\
\mathrm{n}\end{array}$ & $\begin{array}{c}\mathrm{R}_{0} \\
\mathrm{hPa} \cdot l^{-1} \cdot \mathrm{s}\end{array}$ & $\begin{array}{c}\mathrm{P} \\
\times 10^{-3}\end{array}$ & $\begin{array}{c}\mathrm{FPa} \cdot l^{-1} \cdot \mathrm{s}^{2} \\
\mathrm{~Hz}\end{array}$ \\
\hline $\begin{array}{l}\text { Baseline } \\
\text { Methacholine }\end{array}$ & 119 & $2.7 \pm 0.8$ & $9.2 \pm 20.3$ & $10.1 \pm 2.9$ \\
100 & $\mu \mathrm{g}$ & 119 & $3.0 \pm 1.0$ & $2.2 \pm 29.7$ & $11.1 \pm 4.2$ \\
300 & $\mu \mathrm{g}$ & 119 & $3.3 \pm 1.2$ & $-9.8 \pm 39.4$ & $12.6 \pm 5.5$ \\
600 & $\mu \mathrm{g}$ & 118 & $3.6 \pm 1.3$ & $-17.7 \pm 43.1$ & $14.5 \pm 6.3$ \\
1000 & $\mu \mathrm{g}$ & 115 & $3.9 \pm 1.4$ & $-26.8 \pm 49.6$ & $15.7 \pm 6.9$ \\
\hline
\end{tabular}

Data are presented as mean \pm standard deviation. $\mathrm{R}_{0}$ : resistance; $\mathrm{P}$ : frequency dependence of resistance; F: resonant frequency.
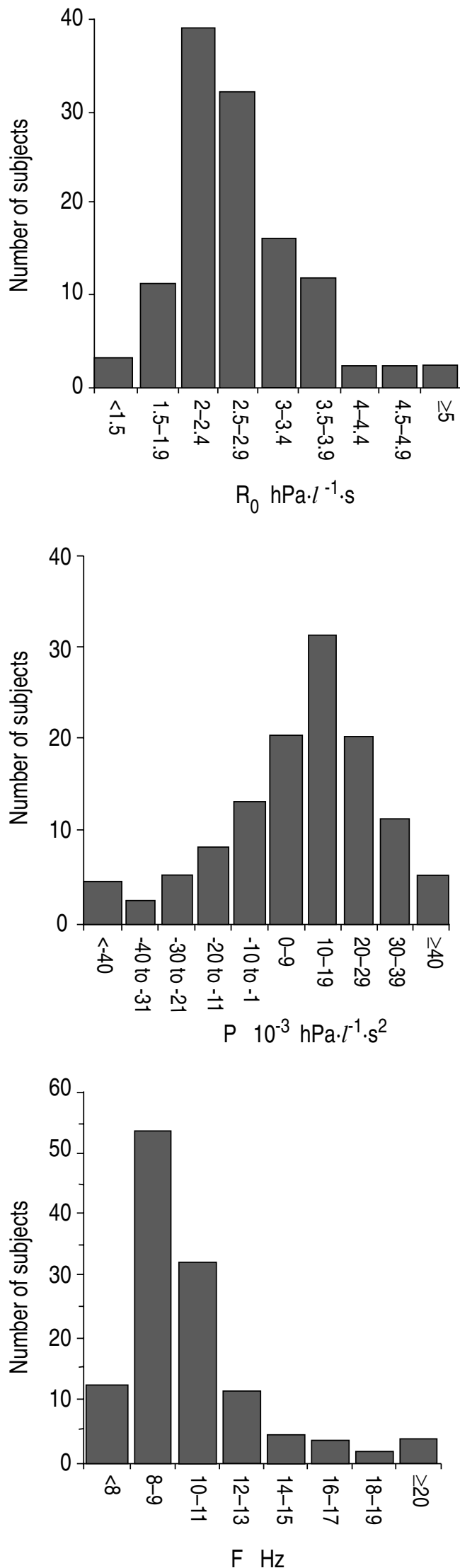

Fig. 1. - Distribution of baseline forced oscillation parameters. $R_{0}$ : resistance. P: frequency dependence of resistance; F: resonant frequency. 
Table 2. - Comparison of functional parameters during bronchial challenge between hyperreactive $\left(\Delta \mathrm{FEV} \mathrm{V}_{1} \%\right.$ $\geq 20 \%)$ and normal subjects $\left(\Delta \mathrm{FEV}_{1} \%<20 \%\right)$

\begin{tabular}{|c|c|c|c|c|c|c|}
\hline \multirow{2}{*}{$\frac{\text { Treatment }}{\text { Baseline }}$} & \multirow{2}{*}{$\begin{array}{c}\begin{array}{c}\text { Functional } \\
\text { parameter }\end{array} \\
\mathrm{R}_{0} \\
\mathrm{P} \\
\mathrm{F}\end{array}$} & \multicolumn{2}{|c|}{$\begin{array}{l}\text { Hyperreactive subjects } \\
\qquad \mathrm{n}=12\end{array}$} & \multicolumn{2}{|c|}{$\begin{array}{l}\text { Normal subjects } \\
\quad \mathrm{n}=107\end{array}$} & $\begin{array}{r}\frac{\mathrm{p}}{\text { value }^{\dagger}} \\
\mathrm{NS}\end{array}$ \\
\hline & & $\begin{array}{l}2.7 \\
3.5 \\
10\end{array}$ & $\begin{array}{l}(1.8-4.9) \\
(-44-32) \\
(8-20)\end{array}$ & $\begin{array}{c}2.6 \\
13 \\
9\end{array}$ & $\begin{array}{l}(1.3-5.4) \\
(-51-48) \\
(6-23)\end{array}$ & $\begin{array}{l}\text { NS } \\
\text { NS } \\
\text { NS }\end{array}$ \\
\hline Methacholine $100 \mu \mathrm{g}$ & $\begin{array}{r}\mathrm{R}_{0} \\
\mathrm{P} \\
\mathrm{F}\end{array}$ & $\begin{array}{l}3 \\
-7.5 \\
13\end{array}$ & $\begin{array}{l}(1.8-6.4) \\
(-117-29) \\
(8-29)\end{array}$ & $\begin{array}{c}2.7 \\
11 \\
9\end{array}$ & $\begin{array}{l}(1.4-5.8) \\
(-83-50) \\
(6-25)\end{array}$ & $\begin{array}{l}\text { NS } \\
* \\
* *\end{array}$ \\
\hline Methacholine $300 \mu \mathrm{g}$ & $\begin{array}{r}\mathrm{R}_{0} \\
\mathrm{P} \\
\mathrm{F}\end{array}$ & $\begin{array}{c}3.7 \\
-37.5 \\
17\end{array}$ & $\begin{array}{l}(1.4-7.5) \\
(-203-23) \\
(10-30)\end{array}$ & $\begin{array}{r}3 \\
3 \\
10\end{array}$ & $\begin{array}{l}(1.4-6.5) \\
(-123-44) \\
(6-28)\end{array}$ & $\begin{array}{r}\mathrm{NS} \\
* * \\
* * *\end{array}$ \\
\hline Methacholine $600 \mu \mathrm{g}^{*}$ & $\begin{array}{r}\mathrm{R}_{0} \\
\mathrm{P} \\
\mathrm{F}\end{array}$ & $\begin{array}{l}4.3 \\
-64 \\
21\end{array}$ & $\begin{array}{l}(1.8-7.5) \\
(-157-30) \\
(11-30)\end{array}$ & $\begin{array}{l}3.4 \\
-5 \\
12\end{array}$ & $\begin{array}{l}(1.5-7.7) \\
(-132-53) \\
(6-32)\end{array}$ & $\begin{array}{r}* \\
* * \\
* * *\end{array}$ \\
\hline Methacholine $1000 \mu \mathrm{g} * *$ & $\begin{array}{r}\mathrm{R}_{0} \\
\mathrm{P} \\
\mathrm{F}\end{array}$ & $\begin{array}{c}4.9 \\
-83 \\
25.5\end{array}$ & $\begin{array}{l}(3-8) \\
(-188-18) \\
(14-34)\end{array}$ & $\begin{array}{l}3.6 \\
-8.5 \\
13 \\
\end{array}$ & $\begin{array}{l}(1.6-9.9) \\
(-207-53) \\
(7-33)\end{array}$ & $\begin{array}{r}* \\
* * \\
* * *\end{array}$ \\
\hline
\end{tabular}

Data are presented as median, and range in parenthesis. $\mathrm{R}_{0}: \mathrm{hPa} \cdot l^{-1} \cdot \mathrm{s} ; \mathrm{P}: 10^{-3} \mathrm{hPa} \cdot l^{-1} \cdot \mathrm{s}^{2} ; \mathrm{F}: \mathrm{Hz} ;$ : Wilcoxon nonparametric test; *: values of $\mathrm{R}_{0}, \mathrm{P}$ and $\mathrm{F}$ were calculated from only 11 hyperreactive subjects; **: values of $\mathrm{R}_{0}, \mathrm{P}$ and $\mathrm{F}$ were calculated from only 9 hyperreactive subjects and 106 normal subjects. $\triangle \mathrm{FEV}_{1}$ : change in forced expiratory volume in one second; NS: nonsignificant. For further abbreviations see legend to table 1.

In the study sample, $10 \%$ of the subjects were considered to be hyperreactive $\left(\Delta \mathrm{FEV}_{1} \% \geq 20 \%\right)$. The three forced oscillation parameters were significantly different according to the presence of $20 \% \Delta \mathrm{FEV}_{1}$ during the methacholine challenge test (table 2) except for $\mathrm{R}_{0}$ at the doses of 100 and $300 \mu \mathrm{g}$. Higher $\mathrm{R}_{0}$, more negative frequency dependence of resistance and higher resonant frequency were observed among the hyperreactive subjects compared to normal subjects $\left(\triangle \mathrm{FEV}_{1} \%<20 \%\right)$. The difference in dose-response slope was highly significant for $\mathrm{R}_{0}$ between hyperreactive and normal groups, the former exhibiting a higher value than the latter (data not shown). As expected, none of the baseline respiratory parameters of either method were able to distinguish between subjects according to BHR. Spirometric and forced oscillation indices were significantly correlated, as correlation coefficients of $\Delta \mathrm{R}_{0} \%, \Delta \mathrm{P}$, and $\Delta \mathrm{F} \%$ with $\Delta \mathrm{FEV}_{1} \%$ were $0.37(\mathrm{p}<0.001),-0.42(\mathrm{p}<0.001)$ and 0.39 $(\mathrm{p}<0.001)$, respectively. Moreover, correlation coefficients of the dose-response slope of $\mathrm{R}_{0}, \mathrm{P}$ and $\mathrm{F}$ with the dose-response slope of $\mathrm{FEV}_{1}$ were even higher $(0.58$ $(\mathrm{p}<0.001) ;-0.60(\mathrm{p}<0.001)$; and $0.56(\mathrm{p}<0.001)$, respectively).

Figure 2 shows ROC curves corresponding to the sensitivity and specificity of change in FOT parameters compared to $\Delta \mathrm{FEV}_{1} \%$. The cut-off point values of $\Delta \mathrm{R}_{0} \%$, $\Delta \mathrm{P}$, and $\Delta \mathrm{F} \%$ with the largest number of well-classified subjects according to the $20 \% \Delta \mathrm{FEV}_{1}$ were as follows; 1) for $\Delta \mathrm{R}_{0} \%$, an increase of $65 \%$ corresponded to $75 \%$ sensitivity and $76 \%$ specificity; 2 ) for $\Delta \mathrm{P}$, a decrease of $65 \times 10^{-3} \mathrm{hPa} \cdot l^{-1} \cdot \mathrm{s}^{2}$ corresponded to a sensitivity of $58 \%$ and a specificity of $83 \%$; and 3 ) for $\Delta \mathrm{F} \%$, an increase of $50 \%$ corresponded to a sensitivity of $75 \%$ and a specificity of $62 \%$.

Overall the choice of 15 and $10 \% \Delta \mathrm{FEV}_{1}$ gave no additional information for the determination of the best sensitivity and specificity of change in FOT parameters.

\section{Discussion}

For clinical purposes, the $\mathrm{FEV}_{1}$ derived indices during challenge tests have demonstrated their sensitivity and reproducibility in distinguishing between asthmatic and nonasthmatic subjects $[8,18,23]$. However, deep inspiration before recording $\mathrm{FEV}_{1}$ could affect bronchial tone [9]. Moreover, repetitive spirometry manoeuvres during bronchial challenge are exhausting for the subjects [18]. These two points underlined the advantage of the FOT, which can be easily performed at the workplace with only the passive co-operation of the subjects [15, 24-26]. This method has been used in epidemiological surveys, and has provided complementary information to forced expiration tests in the detection of early airway abnormalities $[12,27,28]$, although it has been criticized because of the influence of the upper airway artefact on the sensitivity of the FOT [12]. The twoparameters model used in our study constitutes a simple method of describing the mean level of resistance and its degree of frequency dependence. The change in frequency dependence of resistance at increasing doses of methacholine is known to reflect increasing airway obstruction, as described by previous authors [13, 29, 30].

The FOT has been used by several investigators for bronchial challenge tests in children $[13,14]$ and in asthmatic subjects with different degrees of airway obstruction $[15,16,25,29-32]$. To our knowledge, this study is the first attempt to evaluate the usefulness of this method to measure bronchial hyperresponsiveness in active workers.

Concerning the comparison between hyperresponsive (hyperreactive) and nonresponsive (normal) subjects, we found that the dose-response slope in particular, was more pronounced for $\mathrm{R}_{0}, \mathrm{P}$ and $\mathrm{F}$ for the hyperreactive group of subjects with a $20 \%$ fall in $\mathrm{FEV}_{1}$. This 
a)

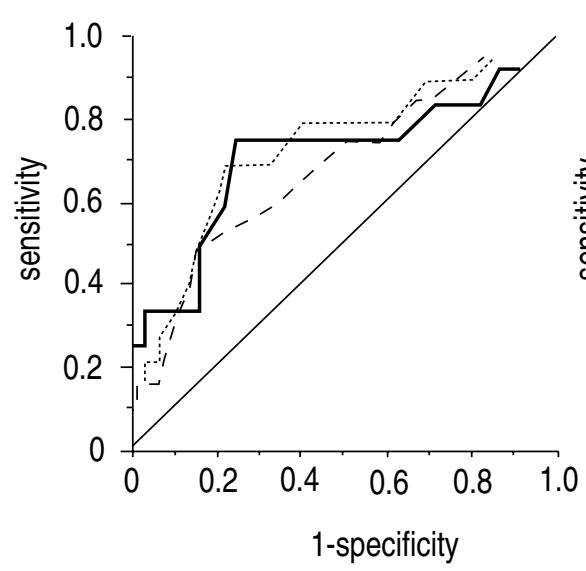

b)

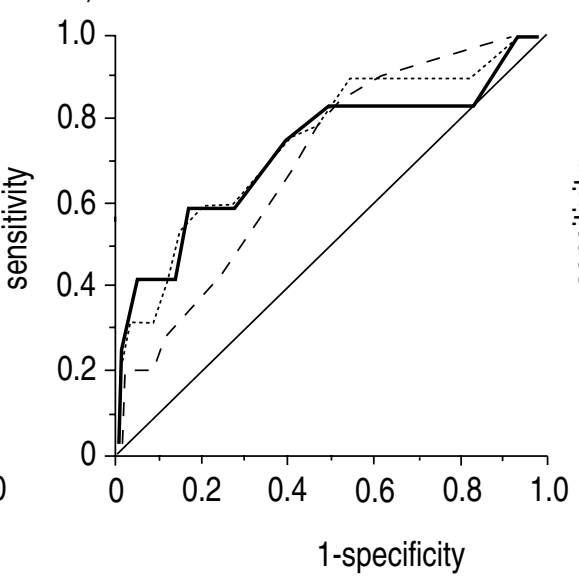

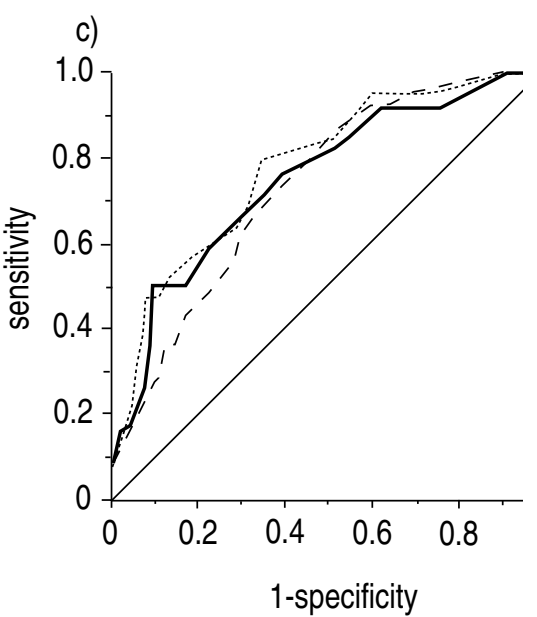

Fig. 2. - Receiver operating characteristics (ROC) curves of : a) $\Delta \mathrm{R}_{0} \%$; b) $\Delta \mathrm{P}$; and c) $\Delta \mathrm{F} \%$ according to 20 , 15 and $10 \%$ fall in $\mathrm{FEV} \mathrm{H}_{1}$. : $\Delta \mathrm{R}_{0} \%, \Delta \mathrm{P}$ and $\Delta \mathrm{F} \%$ vs $20 \% \Delta \mathrm{FEV}_{1} ; \cdots \cdots \cdots \cdots \cdots, \Delta \mathrm{R}_{0} \%, \Delta \mathrm{P}$ and $\Delta \mathrm{F} \%$ vs $15 \% \Delta \mathrm{FEV}_{1} ; \cdots: \Delta \mathrm{R}_{0} \%, \Delta \mathrm{P}$ and $\Delta \mathrm{F} \%$ vs $10 \% \Delta \mathrm{FEV}_{1} . \mathrm{FEV}_{1}$ : forced expiratory volume in one second; $\mathrm{R}_{0}$ : resistance; $\mathrm{P}$ : frequency dependence of resistance; $\mathrm{F}$ : resonant frequency.

was in agreement with BEGIN et al. [15] who observed a similar pattern in a histamine challenge test. WOUTERS et al. [30] could not distinguish normal subjects from asthmatics using baseline values of resistance. However, at the end of the histamine test, differences in mean resistance and resistance at low frequencies were highly significant between both groups.

In our study, we observed significant correlations between $\%$ fall in $\mathrm{FEV}_{1}$ and \% increase in $\mathrm{R}_{0}$, and between $\%$ fall in $\mathrm{FEV}_{1}$ and decrease in $\mathrm{P}$, with, however, lower coefficients than those reported in previously published studies. Most investigators found significant correlations between changes in $\mathrm{FEV}_{1}$ and changes in resistance at low frequency using various indices (13-16), in asthmatic patients or in subjects with various degrees of bronchial obstruction.

The ROC curves [20, 22], which simultaneously present the sensitivity and specificity of a diagnostic procedure, can be used to determine the cut-off points corresponding to the best discrimination of subjects according to the reference method. The thresholds in variation of forced oscillation parameters corresponding to the greatest number of subjects correctly classified according to the $20 \% \Delta \mathrm{FEV}_{1}$, showed sensitivities ranging between $58-75 \%$ and specificities between $62-83 \%$. These values could be considered fairly good, although higher values have been observed. To distinguish between asthmatic and nonasthmatic subjects, Wouters et al. [30] found a sensitivity of $92 \%$ and a specificity of $61 \%$ with the so-called conductance parameter $\left(\mathrm{R}_{8 \mathrm{HZ}} /\left(\mathrm{R}_{8 \mathrm{~Hz}}{ }^{2}+\mathrm{X}_{8 \mathrm{HZ}}{ }^{2}\right)\right.$, where $\mathrm{X}$ is the reactance) at low frequencies, during a histamine test. VAN NOORD et al. [29] examined three methods of measurement of BHR: plethysmography, forced expiratory manoeuvres and FOT, in 53 asthmatic subjects. Using a multivariate analysis with the $40 \%$ decrease in specific conductance or $15 \%$ decrease in $\mathrm{FEV}_{1}$ as dependent variable, the authors showed that the most relevant parameters were the specific conductance, $\mathrm{FEV}_{1}$ and the reciprocal of $\mathrm{R}_{6 \mathrm{~Hz}}$ and that of mean resistance. The sensitivity of the technique of forced oscillation used in the present study was compared to plethysmography by CHINET et al. [31] in normal and asthmatic subjects. According to the authors, the two techniques provided comparable information for the measurement of bronchial responsiveness.

Some factors may have contributed to a low accuracy of the sensitivity and specificity of FOT in our study. In particular, the prevalence of hyperreactivity was rather low $(10 \%)$. In the studies conducted in the general population, the prevalence of hyperreactivity varied from 10-25\% [33-36]. With the maximal dose of 1,000 $\mu \mathrm{g}$, which was lower than the usual dose of $2,000 \mu \mathrm{g}$ to $5,000 \mu \mathrm{g}[2,21]$, we certainly underestimated the percentage of responders.

In conclusion, this study is the first reported application of the measurement of bronchial reactivity by the FOT in an active working population. Comparison with forced expiratory manoeuvres showed a significant correlation between the $\mathrm{FEV}_{1}$ variation during the methacholine challenge test and variation of the resistance, frequency dependence and resonant frequency, allowing the determination of the corresponding values of the FOT indices of hyperreactive subjects. The differences between hyperreactive and normal subjects were highly significant for these parameters. These preliminary results demonstrate the usefulness of the FOT for assessment of bronchial reactivity in occupational epidemiology. However, further studies are needed in subjects with different occupational exposures.

Acknowledgments: The authors gratefully acknowledge Prof. A. Ghachem and Prof. M. Maalej for their collaboration in this study, and Q.T. Pham (INSERM U115) for his helpful comments during preparation of the manuscript.

\section{References}

1. Enarson DA, Chan-Yeung M, Tabona M, Kus J, Vedal S, Lam S. Predictors of bronchial hyperexcitability in grain-handlers. Chest 1987; 4: 452-455. 
2. Hendrick DJ, Fabbri LM, Hughes JM, et al. Modification of the methacholine inhalation test and its epidemiologic use in polyurethane workers. Am Rev Respir Dis 1986; 133: 600-604.

3. Iversen M, Dahl R, Juel Jensen E, Korsgaard J, Hallas $\mathrm{T}$. Lung function and bronchial reactivity in farmers. Thorax 1989; 44: 645-649.

4. Kongerud J, Soyseth V. Methacholine responsiveness, respiratory symptoms and pulmonary function in aluminium potroom workers. Eur Respir J 1991; 4: 159-166.

5. O'Connor GT, Sparrow D, Weiss ST. The role of allergy and nonspecific airway hyperresponsiveness in the pathogenesis of chronic obstructive pulmonary disease. Am Rev Respir Dis 1989; 140: 225-252.

6. Kennedy SM. Acquired airway hyperresponsiveness from nonimmunogenic irritant exposure. Oсcup Med 1992; 7: 287-300.

7. Pham QT, Mur JM, Chau N, Gabiano M, Henquel JC Teculescu D. Prognostic value of acetylcholine challenge test: a prospective study. $\mathrm{Br} J$ Ind Med 1984; 41: 267-271.

8. SEPCR Working group "Bronchial hyperreactivity". Guidelines for standardization of bronchial challenges with (nonspecific) bronchoconstricting agents. Bull Eur Physiopathol Respir 1983; 19: 495-514.

9. Orehek J, Nicoli MM, Delpierre S, Beaupré A. Influence of the previous deep inspiration on the spirometric measurement of provoked bronchoconstriction in asthma. Am Rev Respir Dis 1981; 123: 269-272.

10. Michaelson ED, Grassman ED, Peters WR. Pulmonary mechanics by spectral analysis of forced random noise. J Clin Invest 1975; 56: 1210-1230.

11. Pelle G, Lorino AM, Lorino H, Mariette C, Harf A. A microcomputer-based system to calculate respiratory impedance from forced random noise data. Med Biol Eng Comput 1986; 24: 541-544.

12. Peslin R, Pham QT, Teculescu D, Gallina C, Duvivier C. Comparative value of respiratory input and transfer impedances in field studies. Bull Eur Physiopathol Respir 1987; 23: 37-42.

13. Duiverman EJ, Neijens HJ, Van der Snee-van Smaalen M, Kerrebijn KF. Comparison of forced oscillometry and forced expirations for measuring dose-related responses to inhaled methacholine in asthmatic children. Bull Eur Physiopathol Respir 1986; 22: 433-436.

14. Lebecque P, Spier S, Lapierre JG, Lamarre A, Zinman $\mathrm{R}$, Coates AL. Histamine challenge test in children using forced oscillation to measure total respiratory resistance. Chest 1987; 92: 313-318.

15. Begin R, Cantin A, Landser FJ. Résistance respiratoire par oscillation forcée et VEMS pour évaluer la réactivité bronchique non spécifique. Rev Mal Respir 1988; 5: 389-392.

16. Snashall PD, Parker S, Ten Haave P, Simmons D, Noble MIM. Use of an impedance meter for measuring airways responsiveness to histamine. Chest 1991; 99: 11831185.

17. Quanjer PH. Standardized lung function testing. Bull Eur Physiopathol Respir 1983; 19 (Suppl. 5): 1-95.

18. Sterk PJ, Fabbri LM, Quanjer PH, et al. Airway responsiveness. Standardized challenge testing with pharmacological, physical and sensitizing stimuli in adults. Eur Respir J 1993; 6 (Suppl. 16): 53-83.

19. Bruschi C, Cerveri I, Zoia MC, Maccarini L, Grassi M, Rampulla C. Bronchial responsiveness to inhaled me- thacholine in epidemiological studies: comparison of different indices. Eur Respir J 1989; 2: 630-636.

20. Eliasson AH, Phillips Y, Krishnan R, Rajagopal R, Howard RS. Sensitivity and specificity of bronchial provocation testing. Chest 1992; 102: 347-355.

21. O'Connor G, Sparrow D, Taylor D, Segal M, Weiss S. Analysis of dose-response curves to methacholine. Am Rev Respir Dis 1987; 136: 1412-1417.

22. Swets JA. ROC analysis applied to the evaluation of medical imaging techniques. Invest Radiol 1979; 14: 109-121.

23. Malo JL. Assessment of airway excitability in epidemiologic surveys. Chest 1985; 87: 413-414.

24. Harf A. La méthode des oscillations forcées (résistance du système respiratoire) est-elle la méthode de choix pour évaluer la bronchoréactivité? Rev Mal Respir 1988; 5: 303-304.

25. Wouters EFM. Total respiratory impedance measurement by forced oscillations: a noninvasive method to assess bronchial response in occupational medicine. Exp Lung Res 1990; 16: 25-40.

26. Demedts M, Van Noord JA, Van De Woestijne KP. Clinical applications of forced oscillation technique. Chest 1991; 99: 795-797.

27. Brochard L, Pelle G, De Palmas J, et al. Density and frequency dependence of resistance in early airway obstruction. Am Rev Respir Dis 1987; 135: 579-584.

28. Jorna T, Koiter N, Slangen J, Henderson P, Wouters E, Borm P. Effects of inorganic dust exposure on lung function measured by spirometry and forced oscillation technique (FOT). Am Rev Respir Dis 1992; 145: A539 (Abstract)

29. Van Noord JA, Clement J, Van de Woestijne KP, Demedts M. Total respiratory resistance and reactance as a measurement of response to bronchial challenge with histamine. Am Rev Respir Dis 1989; 139: 921-926.

30. Wouters EFM, Polko AH, Schouten HJA, Visser BF. Contribution of impedance measurement of the respiratory system to bronchial challenge tests. J Asthma 1988; 25: 259-267.

31. Chinet T, Pelle G, Macquin-Mavier I, Lorino H, Harf A. Comparison of the dose-response curves obtained by forced oscillation and plethysmography during carbachol inhalation. Eur Respir J 1988; 1: 600-605.

32. Kabiraj MU, Rolf C, Simonsson BG. Drug-induced changes in airways obstruction reflected by forced expiratory flows and airway resistance measured with an oscillometric method using quiet breathing. Respiration 1981; 41: 90-95.

33. Cockcroft DW, Berscheid BA, Murdock KY. Unimodal distribution of bronchial responsiveness to inhaled histamine in a random human population. Chest 1983; 83: 751-754.

34. Burney PGJ, Britton JR, Chinn S, et al. Descriptive epidemiology of bronchial reactivity in an adult population: results from a community study. Thorax 1987 ; 42: $38-44$

35. Woolcock AJ, Peat JK, Salome CM, et al. Prevalence of bronchial hyperresponsiveness and asthma in a rural adult population. Thorax 1987; 42: 361-368.

36. Rijcken B, Schouten JP, Weiss ST, Speizer FE, Van der Lende R. The relationship between airway responsiveness to histamine and pulmonary function level in a random population sample. Am Rev Respir Dis 1988; 137: 826832. 